\title{
3D MODEL OF AL ZUBARAH FORTRESS IN QATAR - TERRESTRIAL LASER SCANNING VS. DENSE IMAGE MATCHING
}

\author{
T. KERSTEN ${ }^{\text {a }}{ }^{*}$, K. MECHELKE ${ }^{\mathrm{b}}$ and L. MAZIULL ${ }^{\mathrm{a}}$ \\ ${ }^{a}$ HafenCity University Hamburg, Photogrammetry \& Laserscanning Lab, Überseeallee 16, 20457 Hamburg \\ (thomas.kersten, klaus.mechelke)@hcu-hamburg.de, Lena-Maziull@web.de \\ ${ }^{\mathrm{b}}$ HafenCity University Hamburg, Geodetic Lab, Überseeallee 16, 20457 Hamburg \\ Commission V - WG V/4
}

KEY WORDS: 3D, archaeology, cultural heritage, meshing, reconstruction, virtual

\begin{abstract}
:
In September 2011 the fortress Al Zubarah, built in 1938 as a typical Arabic fortress and restored in 1987 as a museum, was recorded by the HafenCity University Hamburg using terrestrial laser scanning with the IMAGER 5006h and digital photogrammetry for the Qatar Museum Authority within the framework of the Qatar Islamic Archaeology and Heritage Project. One goal of the object recording was to provide detailed 2D/3D documentation of the fortress. This was used to complete specific detailed restoration work in the recent years. From the registered laser scanning point clouds several cuttings and 2D plans were generated as well as a 3D surface model by triangle meshing. Additionally, point clouds and surface models were automatically generated from digital imagery from a Nikon D70 using the open-source software Bundler/PMVS2, free software VisualSFM, Autodesk Web Service 123D Catch beta, and low-cost software Agisoft PhotoScan. These outputs were compared with the results from terrestrial laser scanning. The point clouds and surface models derived from imagery could not achieve the same quality of geometrical accuracy as laser scanning (i.e. 1-2 cm).
\end{abstract}

\section{INTRODUCTION}

In order to be able to fulfil the current high geometrical precision requirements of precise $3 \mathrm{D}$ data recording of large and complex objects geodetic measuring methods, photogrammetric multiimage procedures and terrestrial laser scanning, are used. Nowadays, low-cost systems, which make automatic object reconstruction possible using digital cameras and evaluation procedures from photogrammetry and computer vision, are increasingly available on the market. These budget-friendly procedures use open-source algorithms, such as Structure from Motion or Dense Image Matching, in order to automatically derive 3D models from imagery. However, the accuracy potential of such low-cost systems must still be examined in different applications and, if necessary, must be optimized in relation to metrology aspects (accuracy and reliability).

Practical examples of image-based modelling for the documentation of cultural monuments have been shown by Remondino \& Menna (2008). Remondino et al. (2008) demonstrated that the same results can be obtained with both image-based and range-based procedures for the recording and modelling of monuments .Barazzetti et al. (2009) presented the combined use of photogrammetric and computer vision procedures for the automatic and exact 3D modelling of terrestrial objects. They also showed that similar results can be achieved with image-based and range-based recording systems. Kersten \& Lindstaedt (2012c) showed that image-based modelling supplies geometrically similar results for archaeological finds when compared to a reference structured light system.

In this contribution, such low-cost systems (using the same image data set with open-source software, free software, web services, and low-cost software) are compared with reference data from terrestrial laser scanning that was collected for the huge and complex Al Zubarah fortress in Qatar.

\section{THE AL ZUBARAH FORTRESS, QATAR}

The $\mathrm{Al} \mathrm{Zubarah} \mathrm{fort} \mathrm{is} \mathrm{situated} \mathrm{in} \mathrm{the} \mathrm{historically-important} \mathrm{town}$ of Zubarah, which in turn is located on the north-western coast of the Qatar peninsula in the Madinat ash Shamal municipality. It is located $105 \mathrm{kms}$ from the Qatari capital of Doha (Figure 1). The impressive fortress is one of the most well-known sights and tourist attractions in Qatar with an area of $34 \mathrm{~m} \times 34 \mathrm{~m}$ and a height of $9 \mathrm{~m}$. Near the fortress is the former city Al Zubarah, which was the largest settlement of the country with up to 6.000 inhabitants. It was the centre of the pearl divers from the middle of the 18th up to the beginning of the 20th Century. Today's fortress Al Zubarah was completely rebuilt in 1938 on behalf of Sheikh Abdullah Qasim Al-Thani (1871-1957) approximately 2 $\mathrm{km}$ inland of the former city. This military structure attained a strategic meaning in this location because of the constant conflict with the neighbouring state of Bahrain. Thus, the fortress still served as an important military base even after the independence of Qatar in the year 1971 and up until the middle of 1980s. In 1987 it was renovated into a museum to display diverse exhibits and artworks, particularly contemporary, topical archaeological findings. The square fort consists of solid loam walls, in whose corners three round and one rectangular military tower in the typical Arab architectural style rule are available (Figure 1).

Today the area of the former city, which was abandoned after lengthy military conflicts approx. 100 years ago, is an archaeological excavation site (Richter et al. 2011) for which the status of UNESCO world cultural heritage was requested together with the fortress (Thuesen \& Kinzel 2011). In June 2013 UNESCO added the abandoned historical coastal town $\mathrm{Al}$ Zubarah Archaeological Site (including the Al Zubarah fortress) to the World Heritage List. Zubarah is one of the largest and bestpreserved examples of an 18th-19th century traditional pearl fishing and merchant town in the Gulf. It is the first site in Qatar to be entered on to the UNESCO World Heritage List. In the

\footnotetext{
* Corresponding author
} 


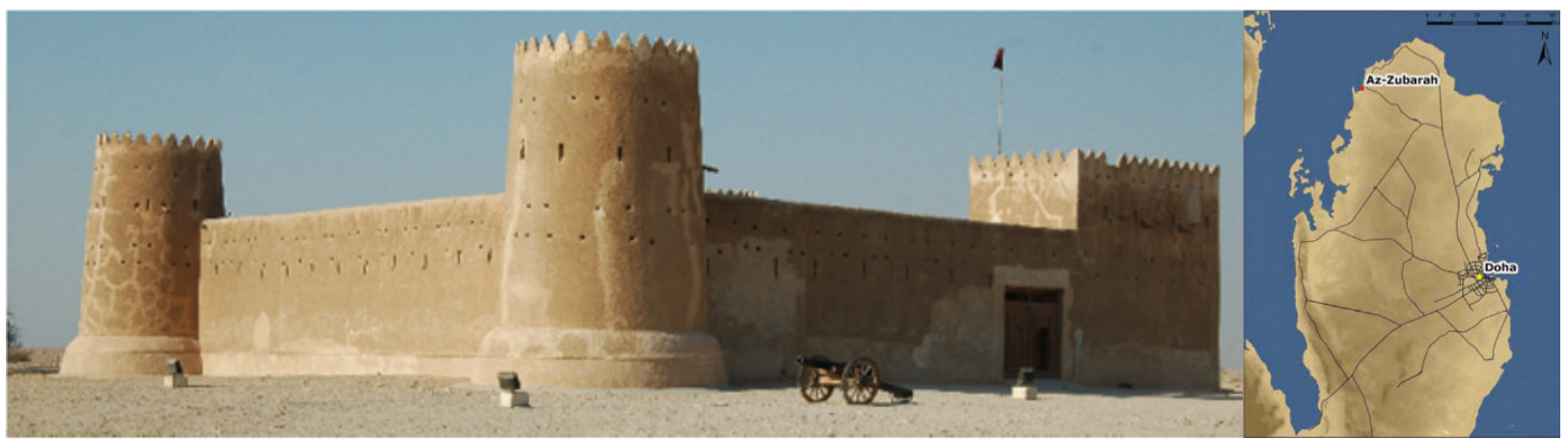

Figure 1: Southern and western facade of the Al Zubarah fortress in Qatar (left), map of Qatar (right)

future a friendship bridge (Qatar Bahrain Causeway) is to be built in this area as a fast connection by car between the two States of Qatar and Bahrain.

\section{INSTRUMENTS AND SOFTWARE USED}

For 3D data acquisition of the fort the terrestrial laser scanning system IMAGER 5006h, manufactured by the company Zoller+Fröhlich in Wangen/Allgäu (Germany), was used. The scans were registered with the software $\mathrm{Z}+\mathrm{F}$ LaserControl and the processed in the software Geomagic Studio. The image data was acquired with a digital reflex camera Nikon D70 $(3008 \times$ 2000 pixels), equipped with a Nikkor zoom lens with a focal length of $35 \mathrm{~mm}$. The automatic generation of 3D point clouds and 3D surface models from the image data was carried out with the following software packages: the open-source software Bundler/PMVS2 (Patch based Multi View Stereo Software; Snavely et al. 2008, Furukawa \& Ponce 2010), the free software VisualSFM (Wu 2007, Wu 2011), both developed by the University of Washington (USA), the low-cost software Agisoft PhotoScan from St. Petersburg, Russia, and the Autodesk Web service 123D Catch beta (Abate et al. 2011). The basis of 123D Catch beta is the software smart3Dcapture from the French company acute3D in Nice, whose basic algorithms are described in Courchay et al. (2010). For automatic operational use of Bundler/PMVS2 the HafenCity University Hamburg (HCU) has developed a graphical user interface (Kersten et al. 2012). VisualSFM and PhotoScan ran their main algorithms on the GPU (graphics processing unit) to significantly speed up the data processing. These above-mentioned software solutions are briefly described in Kersten \& Lindstaedt (2012a, 2012b, and 2012c). Furthermore, they were already used in different projects at HCU Hamburg, in which good results were obtained and good experiences were made for smaller objects (Kersten et al. 2012).

\section{DATA EVALUATION - TERRESTRIAL LASER SCANNING}

The 3D laser scanning of the Al Zubarah Fort was conducted by two people in September 2011 using the scanner IMAGER 5006h. 19 scans around the outside of the object were acquired in approx. $3.5 \mathrm{hrs}$, while 48 scans were acquired inside in $6.5 \mathrm{hrs}$, both using the High scan resolution which corresponds to a grid spacing of $6 \mathrm{~mm}$ at $10 \mathrm{~m}$ distance. As well as the inner court all interiors were also scanned and additional scans were acquired from all four towers in order to achieve better registration between exterior and interior scans. For the registration of the scans only a few targets were fixed inside the building. However, in the area close to the exterior of the fortress paper targets (DIN A4) were fixed on concrete piers while rotatable and swivelling targets with a diameter of $6 \mathrm{~cm}$ were anchored in the ground (Figure 2).

The local registration of 62 scans was carried out with LaserControl using 169 targets. An average deviation of $3.8 \mathrm{~mm}$ was obtained for the targets. Five scans of interiors were not used. For the subsequent RGB colouring of the scans nine photographs were taken after scanning at each scan station in order to compute a full-spherical panorama. Therefore, a Nikon D90 (4288 × 2848 pixels) with a $10.5 \mathrm{~mm}$ Nikkor fisheye lens was used on an optical pivot point adapter (nodal point) at each scan station. The entire point cloud was sampled down to a point spacing of $1 \mathrm{~cm}$ using the software Geomagic Studio. Thus, the data volume could be reduced to 11.6 million points, which were used for further processing of the fortress (Figure 3). After filtering of this point cloud in Geomagic Studio, a 3D mesh of 10 million triangles was generated (Figure 3 right). The processing of the laser scanning data is summarised as follows: ten hours for the acquisition of 67 laser scans, 31 hours for the registration and RGB colouring of all scans in LaserControl, four hours for 3D meshing in Geomagic Studio, resulting in a total of 45 hours for the whole workflow.

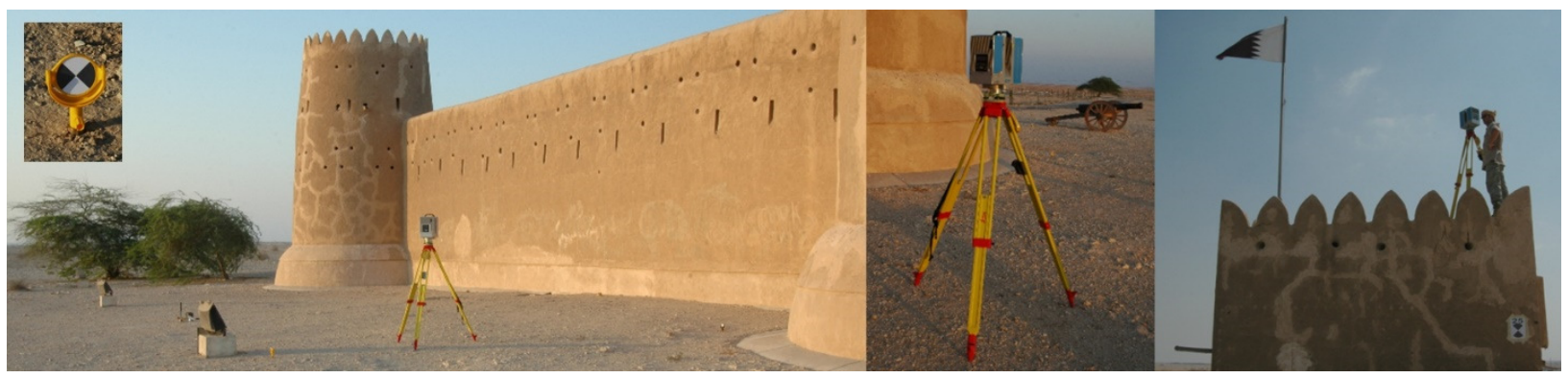

Figure 2: Terrestrial laser scanner IMAGER 5006h in use at fort Al Zubarah 


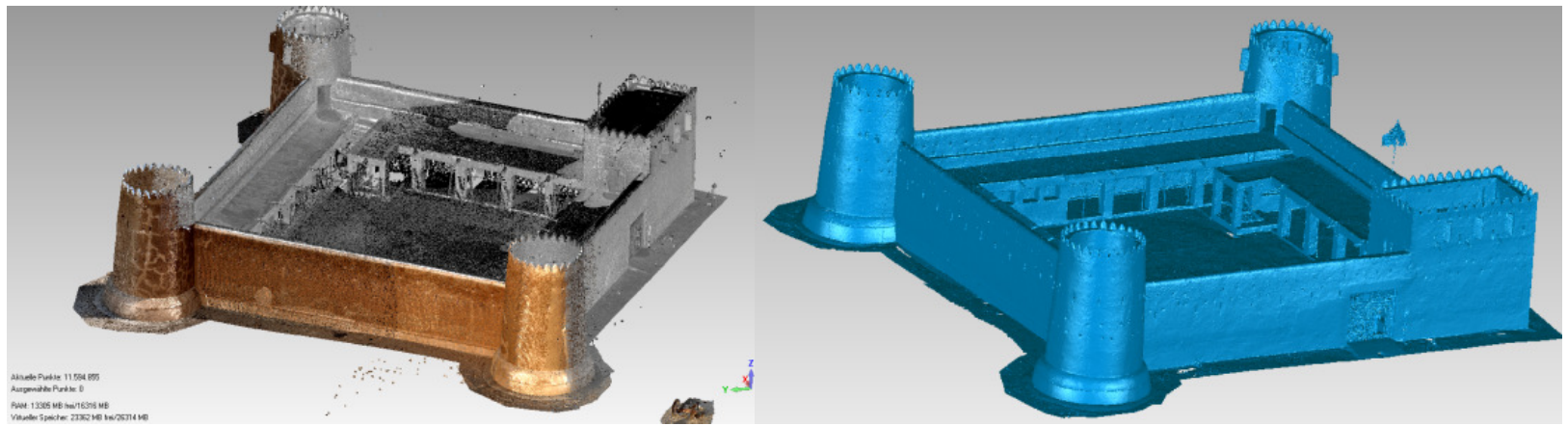

Figure 3: Al Zubarah fortress in Qatar as 3D point cloud (left) and as meshed 3D model (right)

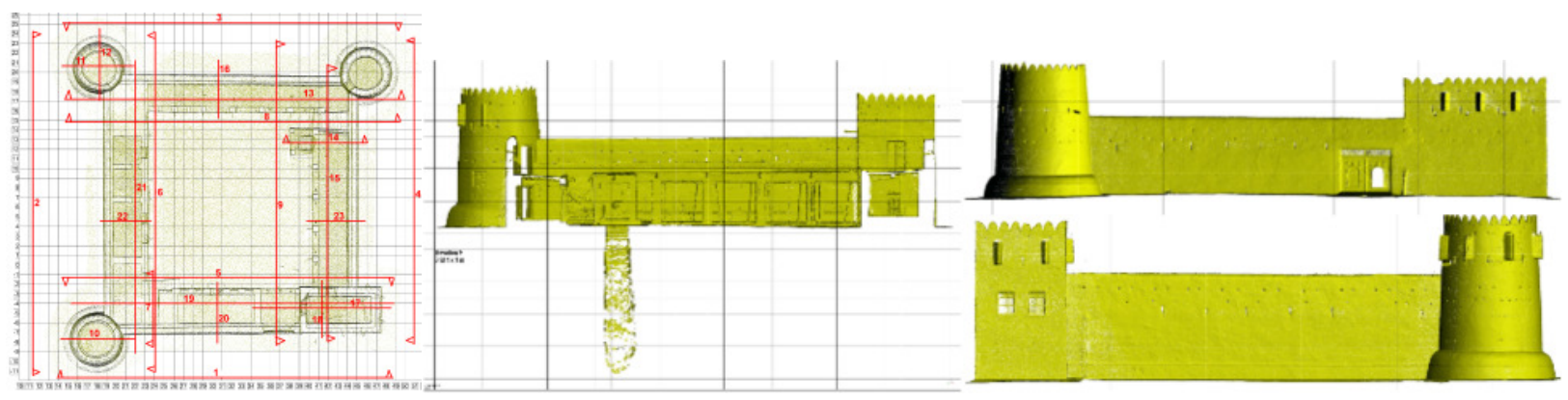

Figure 4: Overview sketch of the exported sections (left), three selected sections of Al Zubarah fortress - interior court yard with water well (centre) and two exterior walls (right)

As basis for the planning of the restoration work, 23 sections (profiles) were exported as DXFs from the point cloud (Figure 4 left). Figure 4 (centre) shows the eastern front of the inner court with water well (section 9) and two sections of the exterior walls as examples of the typical output - section 1 (top right) of the southern exterior facade and section 4 (bottom right) of the exterior eastern front.
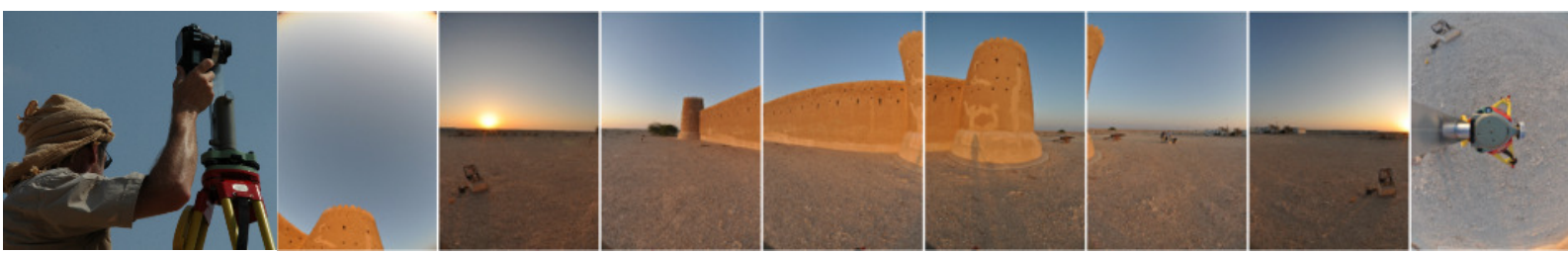

Figure 5: Camera Nikon D90 at the nodal point adapter in use (left) and eight of nine panorama images (right)

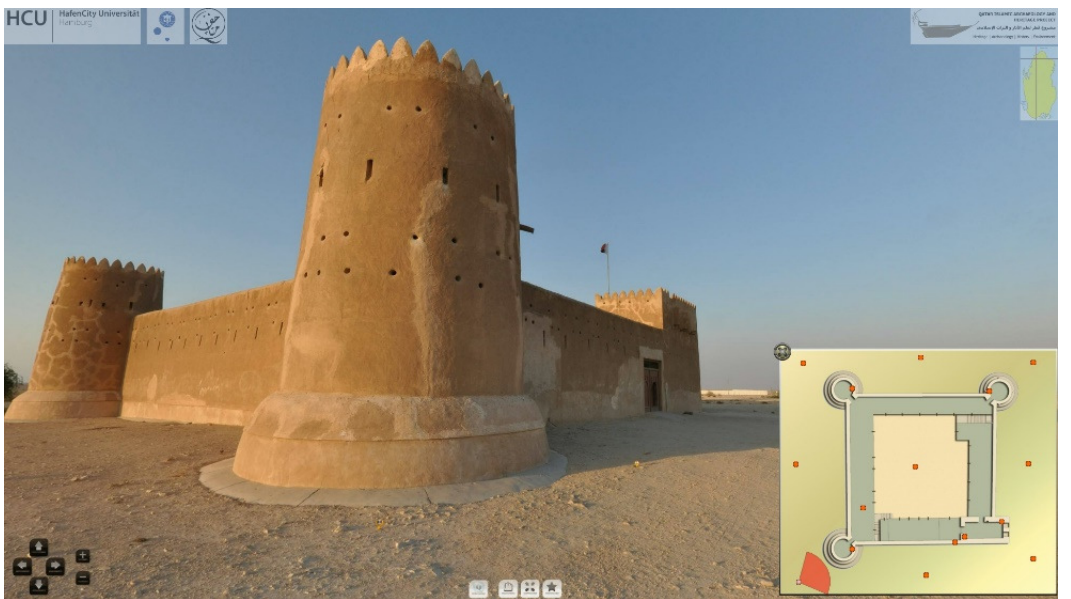

Figure 6: Virtual tour of Al Zubarah fortress using a set of 16 full-spherical panorama images 

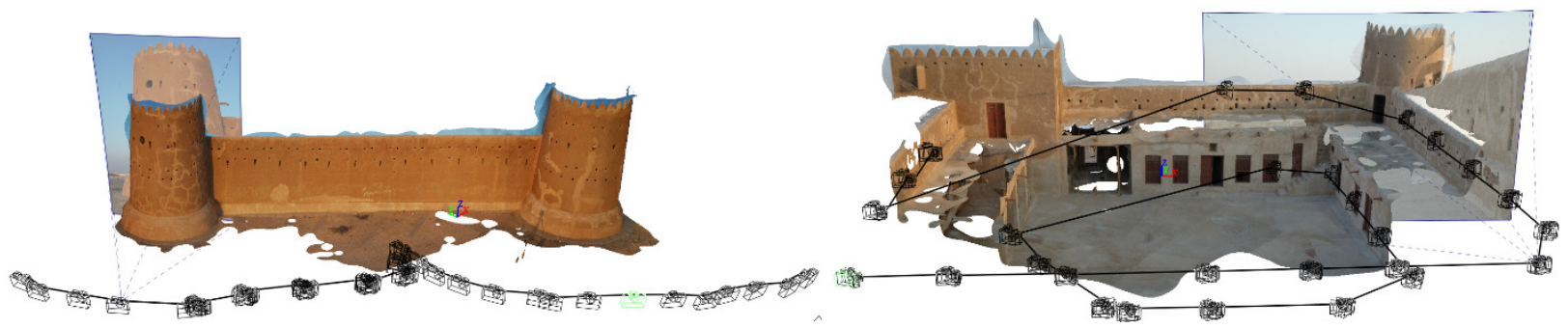

Figure 7: Example for camera positions at Al Zubarah fortress - western exterior wall (left) and southern interior façade (right)

nine photographs were taken on the nodal point adapter, which was fastened to the tripod of the scanner at each scan station one pointing towards the sky, two towards the ground and six photos for the $360^{\circ}$ circle in the horizontal position (Figure 5). The 62 panoramas were automatically computed with the software PTGui V9.04. These panoramas were computed with a low resolution of approx. $6300 \times 3100$ pixels and were afterwards used for the RGB colouring of the point clouds in LaserControl (see Figure 3 left, western front of the fortress). Spherical panoramas with the full resolution of approx. $11700 \times 5850$ pixels (data volume $43 \mathrm{MB}$ ) were also automatically generated to provide a virtual tour of the fortress as a visualisation tool for architects, restorers, and archaeologists and for other project partners. These panorama images were converted into a set of six cube images (in total ca. $5 \mathrm{MB}$ ), while a panorama viewer program simultaneously generated one interactive virtual tour for all available panorama images. Hotspots, an overview map, photographs, text, music, videos and many more custom actions can be integrated using XML-based programming. A connection between different panoramas is created over so-called Hotspots, enabling the viewer to navigate by themselves between these different panoramas. Figure 6 shows the graphical user interface for the interactive virtual tour of the Al Zubarah fortress (www.hcu-laserscanning.de/vt/zubarah/fort_110917/fort.html), in which all spherical panoramas are linked to each other via hotspots or via the overview map (right corner). Thus the user can zoom in and out, rotate the panorama in all directions, and navigate through all panoramas by clicking the hotspots or the marked positions in the map.

\subsection{Imagery for Generation of Points Clouds and 3D Models}

Secondly photographs of the exterior walls and the interior area of the fortress were taken with the Nikon D70 in order to generate 3D point clouds and/or surface models using different software packages. The images were captured without adherence to multiphoto photogrammetric criteria with many photographs taken at eye level. The focal length of the uncalibrated camera was fixed to $35 \mathrm{~mm}$. In Figure 7 an image configuration for an exterior wall and a subrange of the inner court is represented. Altogether 176 photographs were taken for the exterior area and 219 for the interior area of the fortress.

\subsection{Generation of Points Clouds with Bundler/PMVS2 and VisualSFM}

The generation of 3D point clouds with Bundler/PMVS2 and VisualSFM was conducted on a high performance computer (Intel Xeon CPU E5540 processor with $2.53 \mathrm{GHz}, 24 \mathrm{~GB}$ RAM, using the operating system Windows 7 Enterprise 64 bits; status 2011/2012). Due to the high number of photos only the exterior walls of the forts were computed first with both software packages. In Table 1 statistics on the generation of an entire point cloud for the four exterior walls of $\mathrm{Al}$ Zubarah fortress are
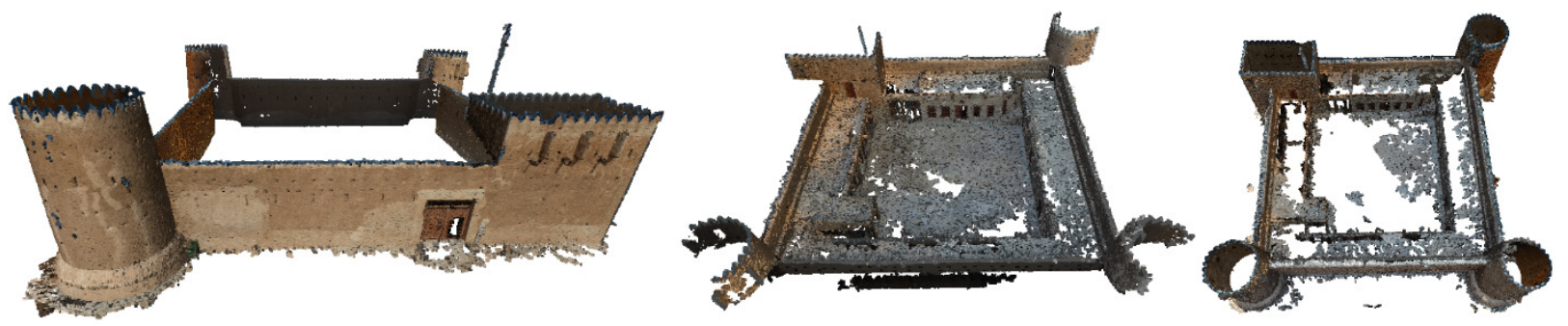

Figure 8: 3D point cloud of the exterior walls (right) and of the court yard (centre) from Bundler/PMVS2, and the entire point cloud of Al Zubarah fortress from VisualSFM (right)

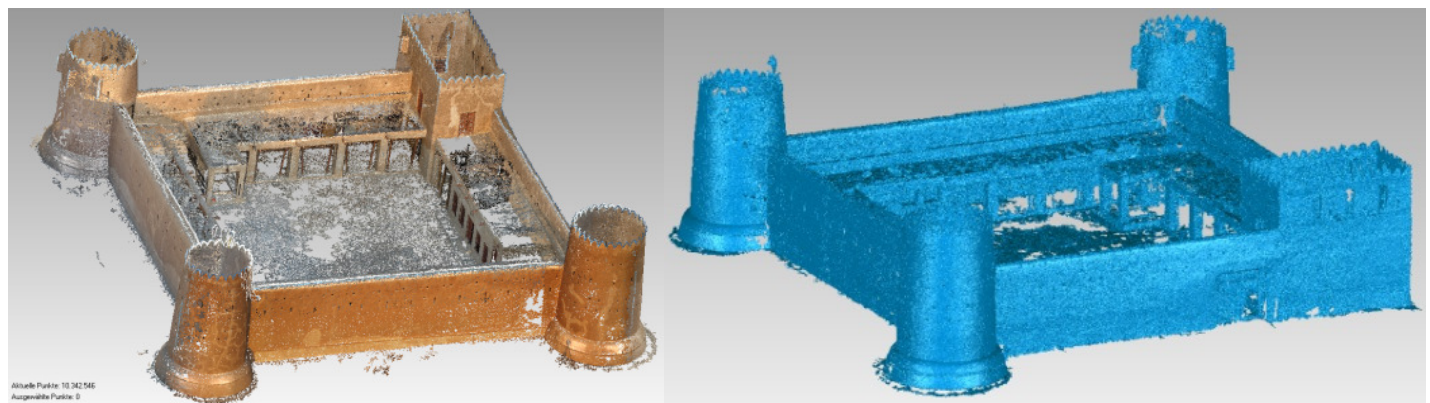

Figure 9: Entire 3D point cloud of the fortress from Bundler/PMVS2 and VisualSFM (left) and 3D model meshed in Geomagic (right) 


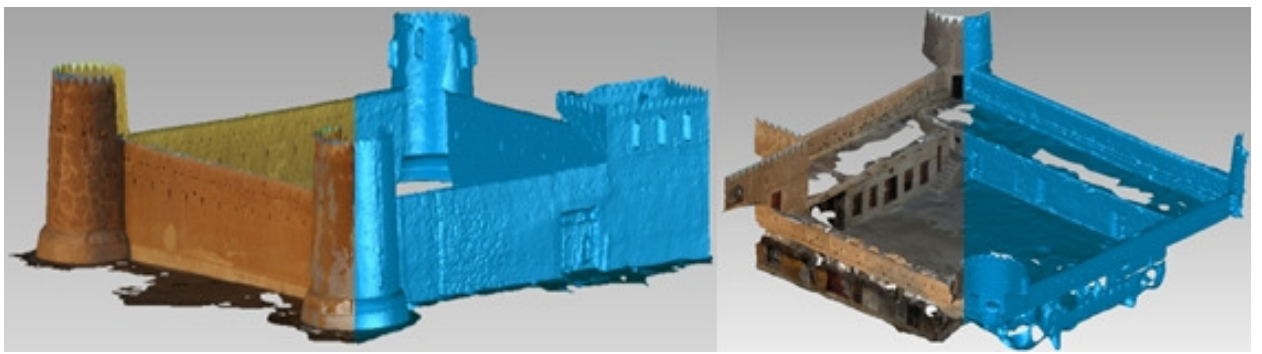

Figure 10: 3D surface model of the exterior walls (left) and the interior area (right) of the fortress Al Zubarah with and without texture generated with Autodesk web service 123D Catch beta

summarised. For the 176 photos the computation time for VisualSFM using the GPU was a factor of 30 faster than Bundler/PMVS2. However, 450,000 fewer points ( 10\%) were counted. The reason for the slight smaller number of points in VisualSFM compared to Bundler/PMVS2 could not be discerned. The point clouds for the exterior walls and interior area from Bundler/PMVS2 are represented in Figure 8 (right and centre).

\begin{tabular}{|l|r|r|r|}
\hline & Visual SFM & Bundler/PMVS2 & Difference \\
\hline \# images & 176 & 176 & 0 \\
\hline \# points & 4.147 .129 & 4.591 .875 & 444.746 \\
\hline Time & $01 \mathrm{hrs} 31 \mathrm{~min}$ & $46 \mathrm{hrs} 08 \mathrm{~min}$ & Factor 1:30 \\
\hline
\end{tabular}

Table 1. Statistics on the point cloud generation of the four exterior walls using different software

In VisualSFM a 3D point cloud $(7,089,119$ points, see Figure 8 right) for the entire fortress could be computed in $3 \mathrm{hrs} 31 \mathrm{~min}$ with an entire image data set of 393 photos, while the task with the same image data had be cancelled after more than 14 days computing time in Bundler/PMVS2 with the computer specified above due to problems with the internal memory (RAM).

All generated point clouds were scaled using different, well distributed reference distances from the laser scanning data. The precision of the reference distances was significantly influenced by the point density within the point cloud, since it was difficult to measure distinctive points in the point clouds depending upon the zoom level used. Conclusively, the entire point cloud from VisualSFM was registered with the dense point cloud of the interior area from Bundler/PMVS2 using a best-fit algorithm in Geomagic Studio with an average deviation of $1.6 \mathrm{~cm}$. In Figure 9 the result of this registration (10.3 million points) and the triangle meshing of the point cloud ( 15.5 million triangles) is illustrated.

\subsection{Generation of Surface Models with Autodesk 123D Catch Beta}

Using 123D Catch beta, a web service of Autodesk, a 3D surface model was computed within 10-20 minutes depending upon data set and/or number of images after the upload of the image data on an external computer server of Autodesk. The user could download the model from the Autodesk server after notification by email. After further data processing the model was sent to the server again for a renewed calculation with maximum resolution offered by the web service. In different tests with the service it was recognized that a data set with more than 100 images had led rather to bad, partial incomplete and incorrect results. Therefore surface models were computed in the maximum resolution for the four exterior and interior fronts using up to 70-80 images (see also Figure 7). The single models of each facade were transferred to Geomagic Studio using the data format OBJ. In Geomagic the individual fronts were manually corrected for blunders. Especially redundant triangles, which particularly represented the sky at the edges of the walls (see Figure 7), were manually marked and deleted. Using measured distances from the laser scanning data the individual exterior and interior fronts were scaled and registered afterwards as separated models for the exterior walls (1.1 million triangles) and the interior area (2.3 million triangles) using ICP algorithms in Geomagic.

Figure 10 shows the 3D models of the exterior walls (average deviation of $1.4 \mathrm{~cm}$ after registration) and of the interior court (deviation $2-3 \mathrm{~cm}$ ) of the Al Zubarah fortress with and without texture. A data fusion of the exterior and interior models could not be realized due to unacceptable geometrical differences and gaps. It can be assumed that these differences are a result of a too small overlap between the models and the insufficient determination of the reference distances by point measurements both within the scan data and the 3D model, although the point identification was much better in the highly resolved textures of the 3D models than in the point clouds. Furthermore, an inhomogeneous scale within the models could be possible.
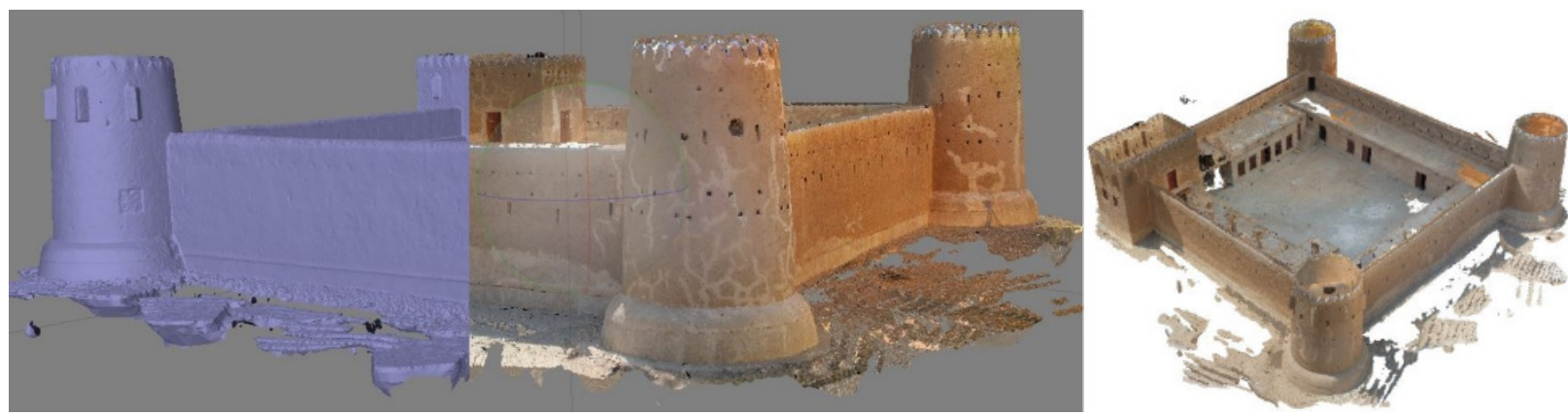

Figure 11: 3D model of the Al Zubarah fortress generated with Agisoft PhotoScan 1.0.4 


\subsection{Generation of Point Clouds and Surface Models with Agisoft PhotoScan}

A third 3D surface model of the fortress was generated with the software Agisoft PhotoScan version 1.0.4 (professional edition). PhotoScan is a multi-view image-based 3D modelling solution for 3D reconstruction of textured mesh models. The general workflow of PhotoScan is as following: add photos (data import), align photos (generation of a sparse point cloud for image orientation using SIFT algorithm and bundle block adjustment), build dense point cloud (dense image matching), build mesh (3D triangulation), and build texture (texture mapping). The advantage of this software is the capability to measure control points in the high resolution images, to use control points in the bundle adjustment, and to use a sophisticated camera calibration model including the calibration parameter focal length, principle point, radial lens distortion (k1-k4), decentring (tangential) distortion (p1, p2), and skew (shearing, defining the angle between the $\mathrm{x}$ and $\mathrm{y}$ pixel axes). For the data processing with PhotoScan the image data set was reduced to 379 images, which covers the exterior walls and the interior area of the fortress. However, the full image data set of 379 images was used as one image block (group/chunk) for the computation in PhotoScan. The computer used for this data processing was different to the computer used with the other software packages: PC Fujitsu Celsius, Intel ${ }^{\circledR}$ Xeon ${ }^{\circledR}$ CPU E5540, 64 Bit processor with four kernels, NVIDIA GeForce GTX 690 VRAM graphic card, 12 GB RAM and Windows 7 as operating system. The following parameters were set for the batch processing workflow: align photos (high accuracy with a point limit of 5 million points), build dense point cloud (high quality, aggressive depth filtering), build mesh (arbitrary surface type, dense point cloud as source data, interpolation enabled, custom face count 6 million), and build texture (generic mapping mode, texture from all cameras, blending mode Mosaic, texture size 3008, texture count 1 , and no colour correction). Five signalised targets were measured in the images, while the $3 \mathrm{D}$ coordinates of these control points were determined in LaserControl. These five ground control points were well-distributed in object space and fixed at the walls of the interior area of the fortress. However, the control point configuration was not optimal, since signalised control points were not available at the exterior walls. Furthermore, the blue sky was manually masked in the images before data processing with PhotoScan. This was necessary to reduce the number of erroneous measurements in the transition between object and sky significantly. The following results were achieved: sparse point cloud for image orientation and camera calibration with 724,495 points, dense point cloud with 36.6 million points and a mesh with 6 million triangles (faces). The residuals of the control points were between $1-2 \mathrm{~mm}$ in the XYZ coordinate. The meshed 3D model of the fortress is illustrated in Figure 11. As a first quality control the horizontal section of the fortress were compared to the reference data (laser scanning). The maximum difference between the image-based and range-based section was $2 \mathrm{~cm}$ (Figure 14 right).

\section{3D MODELS IN COMPARISON}

The 3D models of the Al Zubarah fortress, which were generated with VisualSFM \& Bundler/PMVS2, 123D Catch beta, and with Agisoft PhotoScan, were compared to reference data from laser scanning in Geomagic Studio, in order to evaluate the geometrical quality of the 3D models derived from imagery. For this reason the $3 \mathrm{D}$ point clouds and models derived from images were manually registered to the $3 \mathrm{D}$ reference point cloud and model (from laser scanning data) using 3-4 common points in a first step. In the second step they were automatically registered using an ICP (iterative closest point) algorithm.

The colour-coded deviations between the compared 3D data are illustrated in Figure 12, 13 and 14. The average deviations to the reference data is between $5 \mathrm{~cm}$ and $10 \mathrm{~cm}$ with maximum deviations of approx. $60 \mathrm{~cm}$ for the models generated with scaling by distances. Thus, the quality of the 3D data (point cloud and models) from Bundler/PMVS2 in combination with VisualSFM and 123D Catch beta does not correspond to the high geometrical quality of the laser scanning data for this large object.

Figure 12 shows the 3D point cloud (left), generated with Bundler/PMVS2 and VisualSFM from image data, and the 3D model (right) compared with the reference model from laser scanning data. The green areas in Figure 12 represent the deviations between point cloud and model (from laser scanning), which are smaller than $5 \mathrm{~cm}$ (left), and between the two 3D models, which are smaller than $10 \mathrm{~cm}$ (right). However, it is evident to see in Figure 12 that many areas have also higher deviations, which indicates systematic characteristics from the partial imprecise scaling. The light blue and yellow colours illustrate deviations, which are between $5 \mathrm{~cm}$ and $15 \mathrm{~cm}$ (left) and between $10 \mathrm{~cm}$ and $20 \mathrm{~cm}$ (right).

Slightly smaller deviations are computed in the 3D comparison between the model from the interior court of the fort (derived with 123D Catch beta) and the reference model from laser scanning (Figure 13 left). Most of the areas are green representing deviations of less than $5 \mathrm{~cm}$. Contrary, the result for the exterior walls is the worst of all 3D data, since differences between $5 \mathrm{~cm}$ and $15 \mathrm{~cm}$ (light blue) are predominantly visible (Figure 13 right).

Only the results derived by Agisoft PhotoScan with an average deviation of $2 \mathrm{~cm}$ to the reference were significantly better (Figure 14), since signalised control points were used for the registration of this point cloud, while for the other image-based solution only reference distances were used for the scaling of the dense point clouds. It was not possible to measure the signalised control points in these data sets, since they were fixed on walls of the interior courtyard of the fortress. These results of the 3D comparison show the potential of the image-based software solution for large architectural objects. It could be shown, that instead of object scaling using different reference distances a 3D transformation of the different objects into the reference coordinate system using well-distributed (signalised) control points in object space supplied geometrically better and more reliable results. Therefore, it is necessary to use precise and welldistributed (signalised) control points for the generation of dense point clouds from imagery for large and complex architectural objects. Furthermore, the software used for dense image matching must be capable to use the information of control points (XYZ coordinates and its weights) in a rigorous bundle block adjustment to derive reliable results for image orientation and camera calibration.

\section{CONCLUSION AND OUTLOOK}

In this contribution the investigations showed the fact that beside terrestrial laser scanners used as standard technology for 3D recording also camera-based low-cost systems are able to record and to generate 3D data of large objects such as the Al Zubarah fortress. The data acquisition with cameras is fast, flexible and economical in comparison to laser scanning. However, the geometrical quality of the laser scanning data could not be achieved for all tested software packages using dense image matching, since average deviations between $5 \mathrm{~cm}$ and $10 \mathrm{~cm}$ to the reference model were evaluated. Nevertheless, the results of PhotoScan with average deviations of $2 \mathrm{~cm}$ are geometrically very 


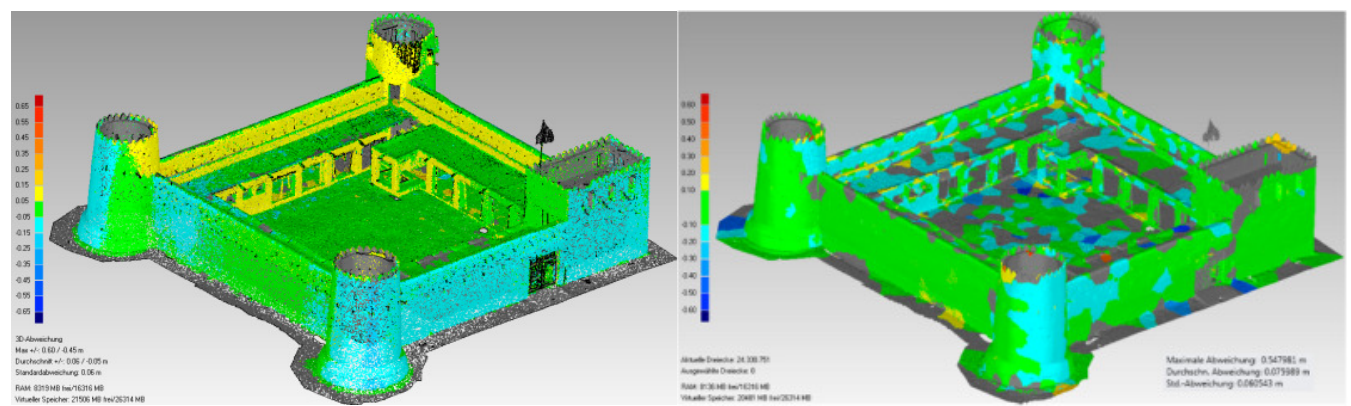

Figure 12: Bundler/PMVS2 \& VisualSFM vs. reference - deviations of the $3 \mathrm{D}$ point cloud (left, green $= \pm 5 \mathrm{~cm})$ and the meshed $3 \mathrm{D}$ model (right, green $= \pm 10 \mathrm{~cm})$

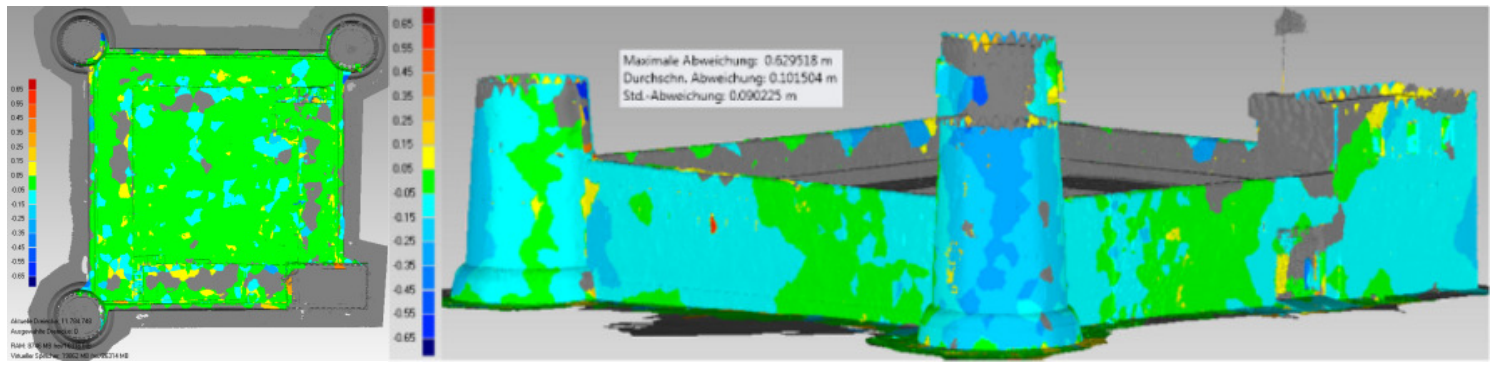

Figure 13: 3D data in comparison - 3D model from laser scanning (IMAGER 5006h) vs. 3D model of the interior area (left) \& $3 \mathrm{D}$ model of the exterior walls (right) from 123D Catch Beta $($ green $= \pm 5 \mathrm{~cm})$
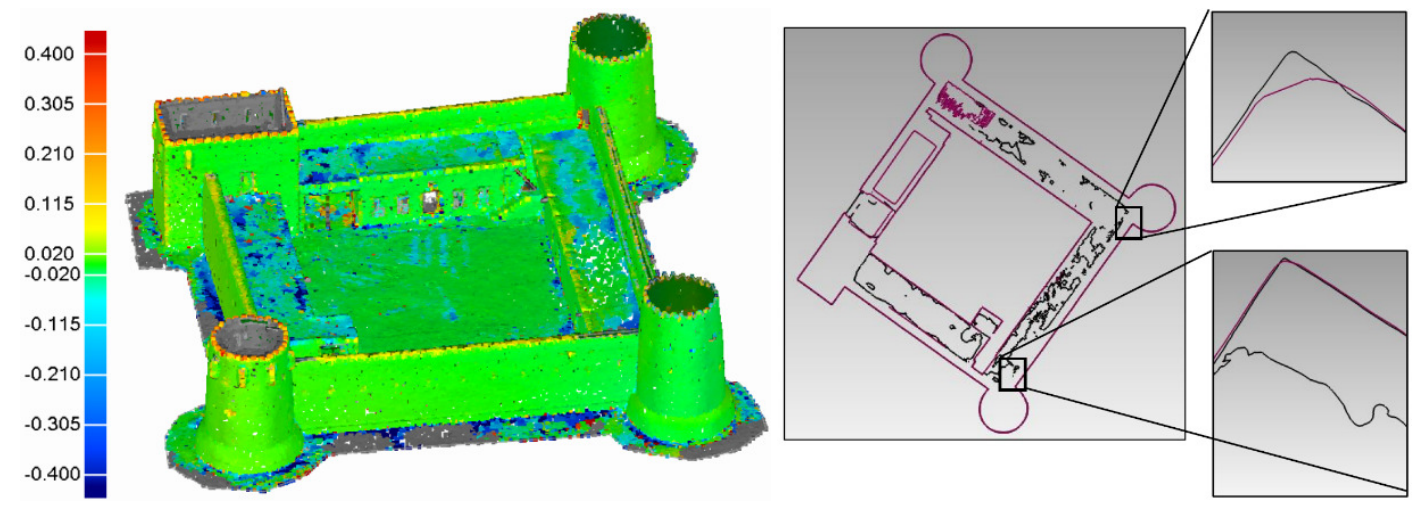

Figure 14: Agisoft PhotoScan - 3D comparison to reference (left) generated in Geomagic (green $= \pm 2 \mathrm{~cm}$ ) and comparison of horizontal sections (black = image-based, red = laser scanning data) with maximum difference of $2 \mathrm{~cm}$ (right)

close to the laser scanning data. Regarding quality and reliability, the limiting factors for the photogrammetric procedure are in general and especially for large objects the photo scale, the lighting conditions, the image block configuration, and the resolution of camera/lens. Also the quality of the measuring procedures as well as the control point determination for scaling or for 3D transformation is of great significance. The comparison of the measuring procedures showed that also image measuring procedures used in Bundler/PMVS2, VisualSFM, 123D Catch beta, and PhotoScan produced results with different quality. To use a camera with higher resolution and qualitatively better lens, could improve the results slightly. However, significantly improved results would have been supplied using a geometrical optimised image configuration by taking photography from elevated positions (e.g. from an Octocopter). The image recording strategy must be changed from classical manual photogrammetric evaluation procedures to automatic point measuring and point transfer methods, which need a higher overlap of the images during the object recording to adapt to the structure-from-motion method. Furthermore, instead of scaling the objects using different reference distances a 3D transformation using well distributed control points will presumably provide reliable results. Nevertheless, the problem of point identification and measurement in 3D data with different resolution will still exist. Kersten \& Lindstaedt (2012c) showed that comparable geometrical quality from terrestrial laser scanners and structure light systems can be achieved for smaller objects (e.g. archaeological finds) using low-cost systems including their measuring procedures in combination with the use of scale bars for object scaling. The performance ability of computers is crucial for the minimisation of data processing time of image data evaluation. Especially for larger objects, which were recorded by a huge number of photographs, the evaluation software must be able to use the computing power of the graphics processing unit (GPU), in order to obtain acceptable computing time. Using the available web services relieve own computer capacities, but data security after the upload of the data is still an open question. Meanwhile there is a large number of algorithms for pixel-based matching in stereo or multi-view images available from the computer vision community providing different 
achievement potential (Scharstein \& Szeliski 2009). Many socalled open-source and/or low-cost software packages for imagebased evaluation will enter the market, in which combined methods from computer vision and photogrammetry are used as new measuring and evaluation procedures. Thus, they constitute a reasonable alternative or addition for range-based measuring systems such as laser scanning or structured light systems (fringe projection), which could herald the start of the beginning of a new development in optical measurement technique. However, further system investigations are necessary to compare the geometrical quality with reference data. Care has to be taken that these procedures fulfil the geodetic and photogrammetric requirements for geometrical quality analysis (metric methodology), which could make further adaptation essential for these procedures.

\section{ACKNOWLEDGEMENTS}

The support of the Qatar Islamic Archaeology and Heritage Project (QIAH), which was launched jointly by the Qatar Museum Authority and the University of Copenhagen (Carsten Niebuhr Centre for Multicultural Heritage, Department of CrossCultural and Regional Studies - ToRS), is gratefully acknowledged.

\section{REFERENCES}

Abate, D., Furini, G., Migliori, S., Pierattini, S., 2011. Project Photofly: New 3D Modelling Online WEB Service. International Archives of Photogrammetry, Remote Sensing and Spatial Information Sciences 38(5/W16), http://www.isprs.org/proceedings/XXXVIII/5-W16/pdf/abate_etal.pdf.

Barazzetti, L. Remondino, F., Scaioni, M., 2009. Combined use of photogrammetric and computer vision techniques for fully automated and accurate 3D modeling of terrestrial objects. Proc. of SPIE Optics+Photonics, Vol. 7447.

Courchay, J., Pons, J.-P., Monasse P., Keriven, R., 2010. Dense and Accurate Spatio-temporal Multi-view Stereovision. Computer Vision - ACCV 2009, Lecture Notes in Computer Science, Volume 5995, pp. 11-22.

Furukawa, Y., Ponce, J., 2010. Accurate, Dense, and Robust Multi-View Stereopsis. IEEE Transactions on Pattern Analysis and Machine Intelligence, 32(8), 2010, 1362-1376.

Kersten, Th., 2007. Virtual Reality Model of the Northern Sluice of the Ancient Dam in Marib/Yemen by Combination of Digital Photogrammetry and Terrestrial Laser Scanning for Archaeological Applications. International Journal of Architectural Computing, Special Focus on Cultural Heritage, 02 (05), Multi-Science, pp. 339-354.

Kersten, Th., Lindstaedt, M., 2012a. Automatic 3D Object Reconstruction from Multiple Images for Architectural, Cultural Heritage and Archaeological Applications Using Open-Source Software and Web Services. Photogrammetrie - Fernerkundung - Geoinformation, Heft 6, pp. 727-740.

Kersten, Th., Lindstaedt, M., 2012b. Potential of Automatic 3D Object Reconstruction from Multiple Images for Applications in Architecture, Cultural Heritage and Archaeology. International Journal of Heritage in the Digital Era, Volume 1, No. 3, a MultiScience Publication, Brentwood, UK, pp. 399-420.
Kersten, Th., Lindstaedt, M., 2012c. Image-Based Low Cost Systems for Automatic 3D Recording and Modelling of Archaeological Finds and Objects. EuroMed 2012 - Int. Conference on Cultural Heritage, Ioannides, M.; Fritsch, D.; Leissner, J.; Davies, R.; Remondino, F.; Caffo, R. (Eds.), Lecture Notes in Computer Science (LNCS), Volume 7616, SpringerVerlag Berlin Heidelberg, pp. 1-10.

Kersten, Th., Lindstaedt, M., Mechelke, K., Zobel, K., 2012. Automatische 3D-Objektrekonstruktion aus unstrukturierten digitalen Bilddaten für Anwendungen in Architektur, Denkmalpflege und Archäologie. 32. WissenschaftlichTechnische Jahrestagung der DGPF, 14.-17. März 2012 in Potsdam, Publikationen der Deutschen Gesellschaft für Photogrammetrie, Fernerkundung und Geoinformation e. V., E. Seyfert (Hrsg.), Vol. 21, Proceedings on CD-ROM.

Remondino, F., Menna, F., 2008 Image-based surface measurement for close-range heritage documentation. International Archives of Photogrammetry, Remote Sensing and Spatial Information Sciences, 37(B5-1), pp. 199-206.

Remondino, F., El-Hakim, S.F., Gruen, A., Zhang, L., 2008. Turning images into 3-D models. IEEE Signal Processing Magazine, 25(4), pp. 55-65.

Richter, T., Wordsworth, P. D., Walmsley, A. G., 2011. Pearlfishers, townsfolk, Bedouin and Shaykhs: economic and social relations in Islamic Al-Zubarah. Proceedings of the Seminar for Arabian Studies, 41, 2011, 317-332.

Scharstein, D., Szeliski, R., 2009. Middlebury Stereo Vision Page. http://vision.middlebury.edu/stereo/, visited at 7.1.2012.

Snavely, N., Seitz, S.M., Szeliski, R., 2008. Modeling the World from Internet Photo Collections. International Journal of Computer Vision, 80(2), pp. 189-210.

Thuesen, I. Kinzel, M., 2011. Al-Zubarah Archaeological Park as a UNESCO World Cultural. Heritage Site - a master plan for its site management, preservation, and presentation (poster). Proceedings of the Seminar for Arabian Studies, 41, pp. 371-376.

Wu, C., 2007. SiftGPU: A GPU implementation of Scale Invariant Feature Transform (SIFT). http://cs.unc.edu/ ccwu/siftgpu.

Wu, C., 2011. VisualSFM: A Visual Structure from Motion System. http://www.cs.washington.edu/homes/ccwu/vsfm/. 